\title{
Selenium deficiency, reversible cardiomyopathy and short-term intravenous feeding
}

\author{
J.B. Levy ${ }^{2}$, H.W. Jones ${ }^{1}$ and A.C. Gordon ${ }^{3}$ \\ ${ }^{1}$ Department of Geratology, ${ }^{2}$ Nuffield Department of Medicine and ${ }^{3}$ Surgery, John Radcliffe Hospital, \\ Oxford OX3 9DU, UK
}

\begin{abstract}
Summary: We report the case of a patient with Crohn's disease receiving short-term postoperative parenteral nutrition supplemented with trace elements who nevertheless became selenium deficient with evidence of a cardiomyopathy. This was fully reversible with oral selenium supplementation. Current parenteral feeding regimes may not contain enough selenium for malnourished patients.
\end{abstract}

\section{Introduction}

Selenium deficiency is well documented to cause cardiac disease both endemically (Keshan disease), ${ }^{1}$ and in patients receiving long-term intravenous feeding. ${ }^{2-5}$ There have been no reports of cardiac dysfunction after short-term postoperative parenteral feeding.

\section{Case report}

A 27 year old man presented with symptomatic tachycardia and chest pain. He had no symptoms of cardiac failure. Two months previously he had been diagnosed as having small bowel Crohn's disease on the basis of a small bowel enema demonstrating multiple strictures. One month later a laparotomy revealed a pre-sacral abscess in addition to active inflammatory bowel disease. An ileostomy was fashioned and parenteral feeding was begun postoperatively with Synthamin $14^{\circledR}$, $60 \%$ glucose and $20 \%$ Intralipid, supplemented daily with trace elements (Additrace) and vitamins (Vitilipid ${ }^{\circledR}$, Multibionta ${ }^{\circledR}$ and folic acid). Parenteral nutrition was continued for 19 days.

Electrocardiogram (ECG) on the current admission confirmed a supraventricular tachycardia rate $180 /$ minute. Serum electrolytes and haemoglobin were all normal. Adenosine intravenously $(21 \mathrm{mg}$ total) failed to terminate the tachycardia. Sinus rhythm was restored by DC cardioversion under general anaesthetic. The ECG post-cardioversion showed global $\mathrm{T}$ wave inversion. Echocardiogram performed the following day revealed a dysfunctional myocardium with moderate diffuse impair-

Correspondence: J.B. Levy, M.D., M.R.C.P. Accepted: 12 August 1993 ment of systolic function and a mildly dilated left ventricle. Ejection fraction was calculated at 0.48 .

He had no further episodes of tachyarrhythmia and was discharged after 3 days. Serum selenium levels at this time were markedly reduced at $0.3 \mu \mathrm{mol} / 1$ (normal $0.8-2 \mu \mathrm{mol} / \mathrm{l}$ ) and red cell glutathione peroxidase activity was also impaired (10 u/g Hb; normal 13-25 u/g Hb).

He was treated with oral selenite $(100 \mu \mathrm{g} / 24$ hours). Repeat echocardiogram one month later showed minimal diffuse hypokinesia (ejection fraction 0.62) and the ECG remained abnormal. After 3 months treatment his electrocardiogram, serum selenium and red cell glutathione peroxidase activity had all returned to normal. Echocardiogram demonstrated good systolic contraction, with ejection fraction 0.70 . There was no clinical history suggestive of viral infection, and antibody titres for coxsackie, influenza, mumps and cytomegalovirus, mycoplasma and psittacosis showed no evidence for recent infection.

\section{Discussion}

Selenium is a trace element present as selenocysteine residues at four catalytic sites in the enzyme glutathione peroxidase. ${ }^{6}$ Whole body selenium has been estimated at approximately $6 \mathrm{mg}$ with a mean positive selenium balance in normal individuals of $0.3 \mu \mathrm{g} /$ day. ${ }^{7}$ Intestinal absorption of food selenium is $80 \%$ of intake, and hospital food provides $65-210 \mu \mathrm{g} /$ day. ${ }^{8}$ Selenium is predominantly excreted in urine $(60-80 \%)$. In patients receiving total parenteral nutrition, negative balances have been demonstrated for selenium, with mean losses of between 11 and $19 \mu \mathrm{g} / \mathrm{day} .^{9,10}$ Deprivation may compromise intracellular antioxidant 
defences and may also increase platelet aggregability by impairing glutathione peroxidase activity in the lipoxygenase pathway. In cattle combined vitamin $E$ and selenium deficiencies can induce preferential degeneration and necrosis within the cardiac conducting system. ${ }^{11}$

Selenium deficiency is endemic in regions of China and causes a dilated cardiomyopathy (Keshan disease) which can be prevented by supplementation. ${ }^{1}$ Similarly myocardial impairment and arrhythmias (ventricular tachycardia and fibrillation) have been associated with selenium deficiency in the setting of long-term parenteral nutrition. ${ }^{2-5}$

This is the first report of cardiac dysfunction and documented selenium deficiency occurring after just 19 days of intravenous feeding, and despite daily selenium supplementation $(0.4 \mu \mathrm{mol}$ or $32 \mu \mathrm{g} /$ day). It is likely that our patient was already selenium deficient prior to surgery and parenteral feeding. Both whole blood and serum selenium deficits have been noted in patients with Crohn's disease, ${ }^{12,13}$ and there is evidence for the malabsorption of other trace elements. ${ }^{14,15}$ It is also possible that bacterial overgrowth in the involved and strictured small bowel contributed to selenium depletion. The element is utilized by both coliform

\section{References}

1. Keshan Disease Research Group of the Clinical Academy of Medical Sciences, Beijing. Epidemiologic studies in the etiologic relationship of selenium and Keshan's disease. Chin Med J 1979, 92: 472-482.

2. Johnson, R.A., Baker, S.S. \& Fallon, J.T. An occidental case of cardiomyopathy and selenium deficiency. $N$ Engl $J$ Med 1981, 304: 1210-1212.

3. Fleming, C.R., Lie, J.T., McCall, J.T. et al. Selenium deficiency and fatal cardiomyopathy in a patient on home parenteral nutrition. Gastroenterology 1982, 83: 689-693.

4. Quercia, R.A., Karn, S., O'Neill, D. et al. Selenium deficiency and fatal cardiomyopathy in a patient receiving long-term home parenteral nutrition. Clin Pharm 1984, 3: 531-535.

5. Lockitch, G., Taylor, G.P., Wong, L.T.K. et al. Cardiomyopathy associated with nonendemic selenium deficiency in a Caucasian adolescent. Am J Clin Nutr 1980, 52: 572-577.

6. Stadtman, T.C. Selenium dependent enzymes. Ann Rev Biochem 1980, 49: 93-100.

7. Stewart, R.D.H., Griffiths, N.M., Thomson, C.D. \& Robinson, M.F. Quantitative selenium metabolism in normal New Zealand women. Br J Nutr 1980, 40: 45-54.

8. Wester, P.O. Trace element balances in two cases of pancreatic insufficiency. Acta Med Scand 1971, 190: 155-161.

9. Jacobson, S. \& Wester, P.O. Balance study of twenty trace elements during total parenteral nutrition in man. Br J Nutr 1977, 37: 107-126. and salmonella species as part of the formate dehydrogenases, ${ }^{16}$ but whether bacterial overgrowth could prevent systemic selenium absorption is not known.

Finally, the standard trace element supplementation (Additrace) contains only $0.4 \mu \mathrm{mol}(32 \mu \mathrm{g})$ selenium. This compares poorly with the absolute minimum requirement to prevent the cardiomyopathy of Keshan disease of $0.24 \mu \mathrm{mol}$ and $0.16 \mu \mathrm{mol}$ per day (19 and $13 \mu \mathrm{g}$ ) for men and women, respectively, and a recommended daily allowance of $0.9 \mu \mathrm{mol}$ and $0.7 \mu \mathrm{mol}$ (70 and $55 \mu \mathrm{g}){ }^{17}$

The possibility of selenium deficiency should be considered in all malnourished patients who receive parenteral nutrition, even if for only a limited period and despite supplementation with trace elements. Selenium status should be monitored in all such patients, with serum selenium levels and erythrocyte glutathione peroxidase activity measured at initiation of intravenous feeding. Patients with borderline or low selenium status should receive supra-normal trace element supplementation. Enzyme activity and serum selenium should be checked after initiation of parenteral nutrition to ensure adequate replacement.

10. Van Rij, A.M., Thomson, C.D., McKenzie, J.M. \& Robinson, M.F. Selenium deficiency in total parenteral nutrition. Am J Clin Nutr 1979, 51: 2076-2085.

11. Kennedy, S. \& Rice, D.A. Selective morphological alteration of the cardiac conduction system in calves deficient in vitamin E and selenium. Am J Pathol 1988, 130: 315-325.

12. Hinks, L.J., Inwards, K.D., Lloyds, B. \& Clayton, B. Reduced concentration of selenium in mild Crohn's disease. $J$ Clin Pathol 1988, 41: 198-201.

13. Jacobson, S. \& Plantin, L.O. Concentration of selenium in plasma and erythrocytes during total parenteral nutrition in Crohn's disease. Gut 1985, 26: 50-54.

14. Galland, L. Magnesium and inflammatory bowel disease. Magnesium 1988, 7: 78-83.

15. Stoll, R., Schmidt, H., Stein, H., Ruppin, H. \& Domschke, W. Functional defect of zinc transport in patients with Crohn's disease. Hepatogastroenterology 1987, 34: 178-181.

16. Stadtman, T.C. Selenium biochemistry. Ann Rev Biochem 1990, 59: $111-157$.

17. Levander, O.A. Scientific rationale for the 1989 recommended dietary allowance for selenium. J Am Diet Assoc 1991, 91: 1572-1576. 